\title{
Correction to: Are Cognitive, Affective, and Eudaimonic Dimensions of Subjective Well-Being Differently Related to Consumption? Evidence from Japan
}

\author{
Tetsuya Tsurumi $^{1}$ (D) $\cdot$ Rintaro Yamaguchi $^{2} \cdot$ Kazuki Kagohashi $^{3} \cdot$ Shunsuke Managi $^{4}$
}

Published online: 18 March 2021

(c) Springer Nature B.V. 2021

\section{Correction to: Journal of Happiness Studies https://doi.org/10.1007/s10902-020-00327-4}

In the original publication, the authors' affiliation has been published incorrectly. The correct affiliation of authors is given in this correction.

Publisher's Note Springer Nature remains neutral with regard to jurisdictional claims in published maps and institutional affiliations.

The original article can be found online at https://doi.org/10.1007/s10902-020-00327-4.

Tetsuya Tsurumi

tsurumi@nanzan-u.ac.jp

1 Faculty of Policy Studies, Nanzan University, 18 Yamazato-cho, Showa-ku, Nagoya 466-8673, Japan

2 National Institute for Environmental Studies, 16-2 Onogawa, Tsukuba 305-8506, Japan

3 Faculty of Global Liberal Studies, Nanzan University, 18 Yamazato-cho, Showa-ku, Nagoya 466-8673, Japan

4 Urban Research Institute and Department of Civil Engineering, School of Engineering, Kyushu University, 744 Motooka, Nishi-ku, Fukuoka 819-0395, Japan 